\title{
Resuscitation decisions in the elderly: a discussion of current thinking
}

\author{
Peter N E Bruce-Jones Bournemouth Hospital, Dorset
}

\begin{abstract}
Decisions about cardiopulmonary resuscitation may be based on medical prognosis, quality of life and patients' choices. Low survival rates indicate its overuse.

Although the concept of medical futility has limitations, several strong predictors of non-survival have been identified and prognostic indices developed. Early results indicate that consideration of resuscitation in the elderly should be very selective, and support "opt-in" policies. In this minority of patients, quality of life is the principal issue. This is subjective and best assessed by the individual in question. Patients' attitudes cannot be predicted reliably and surrogate decision-making is inadequate. Lay knowledge is poor. However, patients can use prognostic information to make rational choices. The majority welcome discussion of resuscitation and prefer this to be initiated by their doctors; many wish to decide for themselves. There is little evidence that this causes distress. The views of such patients, if competent, should be sought actively.
\end{abstract}

Widespread use of cardiopulmonary resuscitation (CPR), originally designed for acute insults, ${ }^{1}$ has prompted calls for its more judicious application. ${ }^{2-5}$ Cardiopulmonary resuscitation is the only medical treatment requiring selection before any need arises. This involves consideration of the medical prognosis, "quality of life" and rights of self-determination. Elderly people are both more likely to suffer illnesses which may lead to cardiorespiratory arrest and to hold opinions influenced by their age, health and related altered circumstances. Unsolicited requests not to be resuscitated are thus sometimes made.

Some countries have adopted formal systems of advance directives. Health consumerism is increasing and CPR has been described publicly as the "last bastion of medical paternalism". ${ }^{6}$ A successful complaint to the Ombudsman regarding the resuscitation status of an elderly lady has led to the publication of several UK guidelines.

\section{Key words}

Resuscitation decisions; "do not resuscitate" orders; advance directives.
This article reviews the literature and discusses the principles involved in resuscitation decisions with particular reference to patient participation.

\section{Ethical principles}

Any treatment is justified by its benefit to the patient. This raises issues of "medical futility" and of "quality of life". Few would dispute that doctors are under no obligation to provide a useless treatment. However, futility depends on the goals of treatment; it is a probability rather than a certainty, and is open to differing interpretations. ${ }^{7}$ Also, the acceptabilif of different outcomes and risks is a value-judgment Quality of life similarly relates to the individuale personality, cultural background, socioeconomie circumstances and health.

Assessments of "quality of life" are subjective and thus arguably outside the legitimate professional role of doctors. Should we therefore incorporate patients' own views? Any rights of patients to self-determination imply a requirement for informed consent. However, authors in both Britain and the USA, including those attaching the greatest importance to patient autonomy, have rejected the notion of $;$ absolute autonomy. ${ }^{5-11}$ There is no right to 3 . demand treatments which are not beneficial ${ }^{58}$ either 8 because the chances for survival are very low or the patient will be unable to achieve "life goals". ${ }^{12}$ To 을 offer choices in the name of autonomy in such circumstances erroneously "implies that there is something at stake for the patient's interests". ${ }^{11}$ This deceives patients, which is contrary to their autonomy, and thus constitutes poor medical $\tilde{O}$ practice..$^{10113}$ By offering only choices relevant to స్ట the situation, the exclusion of interventions with $\sigma$ little chance of success can be seen to enhance 0 patients' autonomy. ${ }^{11}$

Doctors' responsibilities may include (a) the duty $\stackrel{\oplus}{+}$ to save life, (b) defining and advising on the likely 0 benefits of treatment so that the patient may make an informed choice, (c) exercising substituted judgment, (d) acting as the patient's advocate. The primacy of life-saving and the propriety of exercising substituted judgment are debatable. Determination of the absence of medical benefit is a legitimate 
professional duty and it is ethically acceptable for doctors to make resuscitation decisions when survival is unlikely without obtaining consent. ${ }^{8}$

Patients' families are often involved. Doctors prefer to talk to relatives than to patients ${ }^{14}$ and some published guidelines have proposed this ${ }^{15}{ }^{16}$ but in England and Wales families have no rights in law of determination over an adult patient. Their knowledge of CPR and its likely outcome may be poor, as may be their assessment of the patient's attitudes. ${ }^{17-19}$ Family involvement may risk affecting future relationships ${ }^{16}$ and the possibility of selfish motivation cannot be ignored. ${ }^{4}$ This complex position of families adds importance to the doctor's role as the patient's advocate. Importantly, decisionmaking by families is not favoured by patients. Several surveys have found that patients prefer their doctors to decide rather than their families ${ }^{20-23}$ and one found the relatives to do so too. ${ }^{23}$

\section{Outcome from CPR}

Studies show 14-66\% immediate recovery, $0-28 \%$ (average $13-15 \%$ ) discharged alive and $5-17 \%$ alive at six months. ${ }^{24}$ Survival largely depends upon prearrest health. Although there is some disagreement between studies, several factors have been shown to predict poor outcome. Few studies have examined effects on cognitive function, disability or handicap, but there is evidence that survivors may become housebound or more dependent socially. ${ }^{25} 26$

Bedell et al found 95\% mortality after CPR in the presence of hypotension, uraemia, pneumonia, cancer or homebound status, compared with $34 \%$ mortality with none of these, and there were no survivors with sepsis or acute stroke. ${ }^{25}$ Using these results and their own data George et al derived a Prearrest Morbidity Index (PAM) comprising weighted scores for the presence of fifteen different prognostic factors. ${ }^{27}$ No patient scoring more than $8 / 25$ survived to be discharged. O'Keeffe et al found no survivors with a PAM score over 4/25. ${ }^{28}$ The review by Dautzenberg et $a^{24}$ and the meta-analysis by Ebell, ${ }^{29}$ each of which have proposed a modification to the PAM index, have differed in the significance attached to different prognostic factors. Ebell's simpler Prognosis After Resuscitation (PAR) index gives more weight to sepsis and advanced age and treats a primary diagnosis of acute myocardial infarction as a predictor of survival. So far, however, this index has only been tested on the same population studied by O'Keeffe et al. ${ }^{30}$ Limitations of these indices include the lack of uniformity in the factors included, the inclusion of some items for which evidence is limited or conflicting, and the shortage of validation so far.

These indices have not been compared directly with the Acute Physiology And Chronic Health Evaluation (APACHE) scoring system. ${ }^{31}$ This is a well established measure of illness severity in intensive care unit patients, but requires computer- based calculations and is more cumbersome than the PAM and PAR indices. It was derived from an intensive-care patient population and may not be generalisable to all hospital patients. APACHE II has, however, been applied retrospectively to CPR outcome across a hospital. ${ }^{32}$ Most of the predictors of non-survival listed above were confirmed and a score of over 20 had a positive predictive value for death of $96 \%$. APACHE was not originally designed to predict outcome for individuals and several authors have cautioned against such use, ${ }^{33-35}$ although the APACHE III modification aims to do this. ${ }^{36}$

The main concern is incorrect prediction of death in potential survivors. ${ }^{33} 37$ Raising the decision threshold to avoid such false positives lowers the sensitivity. Similarly for the PAM and PAR indices, using a threshold above which there are no survivors (ie $100 \%$ specificity), neither index has displayed a sensitivity for identifying non-survivors of greater than $24 \% .^{27} 30$ Although this might appear to be a severe limitation, in a recent survey using these same thresholds, the two indices used together predicted non-survival of $45 \%$ of mentally competent elderly inpatients. $^{38}$

\section{Patients' attitudes}

About half of British patients lack any knowledge of CPR. ${ }^{2022}$ One study found $80 \%$ claimed awareness of resuscitation, but their knowledge was very limited and derived mainly from television drama. ${ }^{23}$ Over half of patients believe CPR to be usually successful. ${ }^{22}{ }^{23}$ In the USA both patients and doctors overestimate success by up to $300 \% .^{39} 40$

Between $42 \%$ and $92 \%$ of elderly British patients have desired CPR when asked 202231 and in the USA the figure was 41-90\%. ${ }^{17} 184243$ Perceived outcome influences these preferences and the prospect of mental incapacity has a particularly negative effect. ${ }^{20224143}$ Fewer favour CPR once they have been told the chances of a successful outcome. ${ }^{42} 44$ However, a few patients in one study still wanted CPR even if it led to a "hopeless prognosis" or persistent coma. ${ }^{43}$

Patients' attitudes cannot be predicted reliably. Men have appeared to desire CPR more than women ${ }^{2043}$ and older people to want it less than younger. ${ }^{43} 45$ Interpersonal and social factors are important in patients' own estimations of their quality of life and these correlate with their resuscitation preferences. ${ }^{46}$ Recently an association has been shown between the wish of elderly people to die and unmarried status, disability, sensory impairment and institutional living. ${ }^{47}$ There is some evidence that patients desiring CPR are those more independent in daily activities ${ }^{48}$ and one study has found the apparent age and sex differences in resuscitation preference to be accounted for by marital status, with married patients the keenest on CPR and 
widowhood, social isolation and greater dependency associated with a preference not to have CPR. ${ }^{49}$ However, other researchers have found no relationship between patients' resuscitation preferences and their sex, age, diagnosis, functional status or social situation. ${ }^{22} 2350$

Between $67 \%$ and $89 \%$ of patients approve of resuscitation being discussed with them. ${ }^{19-21} 2350$ Studies differ regarding patients' choice of decisionmaker, perhaps because of differences in the precise questions asked. Up to $45 \%$ of patients have wanted to decide for themselves. ${ }^{213949}$ Only a minority of these patients would leave the decision to their doctors but in other studies half or more would do so. ${ }^{2022} 23$ Only a minority of patients want their families to decide for them. ${ }^{20-23}$

Both doctors' and relatives' predictions of patients' preferences are inaccurate. In a study of survivors of CPR most physicians expressed opinions about their patients' attitudes without having had discussions with them, and they failed to recognise that a third of the patients had not wanted CPR. ${ }^{51}$ Doctors underestimate patients' perceived quality of life ${ }^{52}$ but overestimate their wish for $\mathrm{CPR}^{1753}$ as do the patients' spouses. ${ }^{17} 18$

\section{Published guidelines and current practice}

There is consensus that CPR should be used routinely after acute insults, its original role. Based on survival data from Murphy, ${ }^{54}$ Podrid has advocated restriction of CPR in the elderly to those with a single acute illness, no severe underlying chronic disorder, a witnessed arrest and ventricular fibrillation or tachycardia as the initial cardiac dyrrhythmia. ${ }^{55}$ In contrast, Doyal and Wilsher have argued that a high degree of proof of futility is required for such restriction and recommend discussion of resuscitation with all mentally competent patients and the assumption of implied consent to CPR unless a contrary wish is expressed. ${ }^{8}$ Other authorities consider universal patient consent to be impractical but stress the importance of the patient's views if a DNR decision is to be based on the likelihood of a quality of life unacceptable to the patient after CPR. ${ }^{1356}$ The joint British Medical Association and Royal College of Nursing guidelines also recommend discussion with the patient when CPR is unlikely to succeed "to secure understanding and acceptance" of the DNR decision. ${ }^{56}$ They also provide for DNR decisions on the basis of the "recorded and sustained wishes of a mentally competent patient" and recently "living wills" have received legal backing. ${ }^{57}$ Although the British Geriatrics Society guidelines recommend consultation with patients, the sample policy only incorporates unsolicited views. ${ }^{15}$

Documentation of doctors' opinions of patients' suitability for resuscitation is very poor. ${ }^{58}$ Doctors have been found reluctant, even opposed, to consulting with patients about resuscitation, but the vast majority would ask carers. ${ }^{1453}$ In a survey of British Geriatrics Society members, three-quarters of units operated an "opt-out" policy (CPR unless DNR instructions written) and $12 \%$ an "opt-in" policy. However, $12 \%$ followed neither rule, leaving the default position unclear. Equal weight was given to quality of life, chance of success and the underlying medical prognosis; age was the factor least likely to affect decisions.

\section{Patient participation}

There is wide agreement that direct patient involvement in health decisions is necessary if "quality of life" is invoked. Some see this as a moral imperative.$^{8}$ It is popular with the patients and whilst guidelines have generally not favoured canvassing their views ${ }^{15}{ }^{16}$ patients prefer their doctors to initiate the discussion. 5059 Education to overcome poor lay knowledge may be feasible; patients seem able to use this rationally. ${ }^{42}$

Selectivity is required because to offer CPR when it is unlikely to succeed would present an illusory choice, contrary to the principle of autonomy. ${ }^{101113}$ Non-competence and impaired judgment due to acute illness pose practical problems. Although dise cussions may cause some individuals distress, ${ }^{60}$ there is evidence for improvement in psychological wello being. ${ }^{61}$ Occult depression, hidden pleas for help? refusal out of fear of the treatment and patient ambivalence must also be considered. ${ }^{62}$

The timing is important. Discussion on admission to hospital would ensure that any views expressed will be contemporary to the need and may be acceptable alongside the many other questions patients are asked at that time. However, this is also when the acute illness is most likely to affect a patient's judgment and any risk of causing distress may be greater. ${ }^{41}$ Although earlier discussion, perhaps in general practice, may avoid these problems the relevance of these opinions is questionable. Whilst one study found patients' preferences to be stable during a hospital stay, ${ }^{49}$ in another study three of eight patients initially not wanting CPR had changed their minds before discharge. ${ }^{41}$ Neither can the durability of patients' preferences over longer periods be assumed. ${ }^{61}$ Using a deterioration in a patient's clinical condition as the cue may seem most relevant but would deny those without this warning the opportunity to express their views and impaired judgment would remain a problem.

\section{Conclusions}

The low success rate of CPR shows that it is frequently employed when it is futile to do so. There is a clear need for doctors to be better informed about the probable outcome. Notwithstanding their imprecision, greater knowledge and use of predictors 
of outcome, either individually or in prognostic indices, should enable selection of those patients who have a significant chance of survival. The scoring systems first require validation in a wider population. If this confirms the early results, consideration of CPR in the elderly will probably correspond closely to Podrid's criteria ${ }^{55}$ Whilst care must be taken not covertly to incorporate value judgments in these indices, for example by overemphasis of age, employment of such restrictive indications would eliminate many patients with chronic disease and thereby many of the "grey" cases where value judgments are necessary and the difficult question of patient consultation arises.

The assessment of futility inevitably rests on probabilities rather than certainties and it will not be possible to eliminate all value judgments. However, medical responsibilities encompass more than technical expertise. It has been recognised that doctors do legitimately make value judgments on behalf of their patients and set professional ethical standards. ${ }^{1011}$ In order to avoid misuse of the concept of futility it must be based on welldocumented data and a clear and explicit consensus regarding the situations where it applies. ${ }^{5}$ The outcome data and prognostic instruments required are now available and we may be close to the high degree of proof demanded by Doyal and Wilsher, ${ }^{8}$ but society at large must decide on the acceptable probability level. For example, should we accept Schneiderman, Jecker and Jonsen's proposal that failure of a treatment in 100 consecutive cases constitutes futility? ${ }^{12}$

These are clinical decisions but patients want and should be informed about them as provided for in the British Medical Association/Royal College of Nursing guidelines. ${ }^{56}$ Principles of equality and autonomy demand that the views of competent patients should be actively sought when "quality of life" is at stake. Elderly patients want to be consulted, they are able to understand and use prognostic information rationally, no one else can adequately predict their views, and there is little evidence of harm being caused. In order to exercise their autonomy patients need better education on outcomes and risks of interventions such as CPR. The decision whether or not to discuss resuscitation with an individual patient should remain a matter of clinical judgment, but a shift in medical attitudes towards greater openness is required. Physicians must avoid both abusing the concept of futility in order to shirk their responsibility for dialogue with patients, and abusing the principle of autonomy to evade responsible clinical decision-making.

Some authors argue that patients should be informed of DNR decisions even when taken on grounds of clear lack of medical benefit. ${ }^{8}$ However, the right to information about treatment options surely encompasses only those relevant to the clinical situation, and consideration of CPR is not "relevant" when the chances of survival are negligible. To claim otherwise may be elevating CPR to an unwarranted status among treatments. At least in the UK there is no such call for universal discussion of other treatments with little chance of success. Calls for it in CPR are probably a consequence of public (and medical) misconceptions about success rates and probably would not be made if the truth were more widely known. The findings of Murphy may be seen to support this. ${ }^{42}$

When patients are not competent to choose for themselves or express their wishes, their families or doctors may act as surrogates, in either case attempting, however imperfectly, to predict the patient's own attitude and consider it alongside the medical prognosis. As discussed, the relatives' position is compromised. In most such cases the medical prognosis will be a major issue. Advocacy for patients is an accepted medical role. Well-informed doctors are thus best placed to act as surrogate decision-makers, as well as having patients' support for this.

In populations with a high prevalence of serious illness an "opt-in" resuscitation policy seems most appropriate, but this may apply only to geriatric medicine wards. As more units are moving to an integrated admissions policy, it would be useful to know what proportion of inpatients unselected for age would be excluded from resuscitation by indices such as the PAR. There is also a need to know the probability of survival after CPR for the patient 5 remaining after this exclusion has been applied. If this shows CPR to be of clear rather than marginal benefit, it can be selected with similar confidence to other treatments and the cases where quality of life and patients' choice are paramount will then be very few indeed.

There is a trend for published guidelines to be regarded by the courts and other statutory bodies as protocols, and a potential for purchasers of health services to demand a particular policy. Neither is appropriate to the question of resuscitation decisionmaking, because of both the embryonic status of prognostic instruments and the necessity for skilled clinical judgment.

Peter N E fones, $M B, C h B, M R C P$, is Senior Registrar in the Department of Medicine for the Elderly at the Royal Bournemouth Hospital, Bournemouth, Dorset.

\section{References}

1 Kouwenhoven WB, Jude JR, Knickenbocker GG Baltimore MSE. Closed-chest cardiac massage. Fournal of the American Medical Association 1960; 173: 94-7.

2 Anonymous. Right to die [letter]. Lancet 1970; 2: 926.

3 Anonymous. Cardiac resuscitation in hospital: more restraint needed? [editorial]. Lancet 1982; 1: 27-8.

4 Bayliss RIS. Thou shalt not strive officiously. British Medical fournal 1982; 285: 1373-5.

5 Blackhall LJ. Must we always use CPR? New England fournal of Medicine 1987; 317: 1281-4. 
6 BBC Radio Four. The world at one. 1994 Oct 23.

7 Weijer C, Elliott C. Pulling the plug on futility. British Medical fournal 1995; 310: 683-4.

8 Doyal L, Wilsher D. Withholding cardiopulmonary resuscitation: proposals for formal guidelines. British Medical fournal 1993; 306: 1593-6.

9 Lo B, Steinbrook RL. Deciding whether to resuscitate. Archives of Internal Medicine 1983; 143: 1561-3.

10 Jecker NS, Schneiderman LJ. Medical futility: the duty not to treat. Cambridge Quarterly of Healthcare Ethics 1993; 2: 151-9.

11 Tomlinson T, Brody $\mathrm{H}$. Futility and the ethics of resuscitation. Fournal of the American Medical Association 1990; 264: 1276-80.

12 Schneiderman LJ, Jecker NS, Jonsen AR. Medical futility: its meaning and ethical implications. Annals of Internal Medicine 1990; 112: 949-54.

13 Florin D. "Do not resuscitate" orders: the need for a policy. Fournal of the Royal College of Physicians of London 1993; 27: 135-8.

14 Giallombardo E, Homer A. Resuscitation: a survey of policies. Fournal of the British Society of Gerontology 1994; 4: 5-7.

15 British Geriatrics Society. Advice on resuscitation policies, London: BGS, 1993.

16 Williams R. The "do not resuscitate" decision: guidelines for policy in the adult. Fournal of the Royal College of Physicians of London 1993; 27: 139-40.

17 Uhlmann RF, Pearlman RA, Cain KC. Physicians' and spouses' predictions of elderly patients' resuscitation preferences. Fournal of Gerontology 1988; 43: M115-M121.

18 Seckler AB, Meier DE, Mulvihill M, Paris BE. Substituted judgement: how accurate are proxy predictions? Annals of Internal Medicine 1991; 115: 92-8.

19 Morgan R, King D, Prajapati C, Rowe J. Views of elderly patients and their relatives on cardiopulmonary resuscitation. British Medical fournal 1994; 308: 1677-8.

20 Gunasekera NPR, Tiller DJ, Clements LTS-J, Bhattacharya BK. Elderly patients' views on cardiopulmonary resuscitation. Age and Ageing 1986; 15: 364-8.

21 Stolman CJ, Gregory JJ, Dunn D, Levine JL. Evaluation of patient, physician, nurse and family attitudes toward do not resuscitate orders. Archives of Internal Medicine 1990; 150: 653-8.

22 Liddle J, Gilleard C, Neil A. The views of elderly patients and their relatives on cardiopulmonary resuscitation. Fournal of the Royal College of Physicians of London 1994; 28: 228-9.

23 Mead GE, Turnbull CJ. Cardiopulmonary resuscitation in the elderly: patients' and relatives' views. Fournal of Medical Ethics 1995; 21: 39-44.

24 Dautzenberg PLJ, Broekman TCJ, Hooyer C, Schonwetter RS, Duursma SA. Review: Patient-related predictors of cardiopulmonary resuscitation of hospitalised patients. Age and Ageing 1993; 22: 464-75.

25 Bedell SE, Delbanco TL, Cook EF, Epstein FH. Survival after cardiopulmonary resuscitation in the hospital. New England fournal of Medicine 1983; 309: 569-75.

26 Bayer AJ, Ang BC, Pathy MSJ. Cardiac arrests in a geriatric unit. Age and Ageing 1985; 14: 271-6.

27 George AL, Folk BP, Crecelius PL, Campbell WB. Pre-arrest morbidity and other correlates of survival after in-hospital cardiopulmonary arrest. American fournal of Medicine 1989; 87: 28-34.
28 O'Keeffe S, Redahan C, Keane P, Daly K. Age and other determinants of survival after in-hospital cardiopulmonary resuscitation. Quarterly fournal of Medicine 1991; 296: 1005-10.

29 Ebell MH. Prearrest predictors of survival following inhospital cardiopulmonary resuscitation: a metaanalysis. Fournal of Family Practice 1992; 34: 551-8.

30 O'Keeffe S, Ebell MH. Prediction of failure to survive following in-hospital cardiopulmonary resuscitation: comparison of two predictive instruments. Resuscitation 1994; 28: 21-5.

31 Knaus WA, Draper EA, Wagner DP, Zimmerman JE. APACHE II; a severity of disease classification system. Critical Care Medicine 1985; 13: 818-9.

32 Bialecki L, Woodward RS. Predicting death after CPR. Experience at a nonteaching community hospital with a full-time critical care staff. Chest 1995; 108: 1009-17.

33 Atkinson S, Bihari D, Smithies M, Daly K, Mason R, McColl I. Identification of futility in intensive care. Lancet 1994; 344: 1203-6.

34 Pilkington SN. APACHE scoring and prediction of survival in intensive care [letter]. British Medical fournal 1995; 310: 1197.

35 Hyzy RC. ICU scoring and clinical decision making. Chest 1995; 107: 1482-3.

36 Knaus WA, Wagner DP, Draper EA, et al. The APACHE III prognostic system. Risk prediction of hospital mortality for critically ill hospitalised adults. Chest 1991; 100: 1619-36.

37 Rogers J, Fuller HD. Use of daily acute physiology and chronic health evaluation (APACHE) II scores to predict individual patient survival rate. Critical Care Medicine 1994; 22: 1402.

38 Stewart K, Wagg A, Kinirons $M$. When can elderly patients be excluded from discussing resuscitation? Fournal of the Royal College of Physicians of London 1996; 30: 133-5.

39 Miller DL, Jahnigen DW, Gorbien MJ, Simbartl L. Cardiopulmonary resuscitation: how useful? Attitudes and knowledge of an elderly population. Archives of Internal Medicine 1992; 152: 578-82.

40 Miller DL, Gorbien MJ, Simbartl LA, Jahnigen DW. Factors influencing physicians in recommending inhospital cardiopulmonary resuscitation. Archives of Internal Medicine 1993; 153: 1999-2003.

41 Potter JM, Stewart D, Duncan G. Living wills: would sick people change their minds? Postgraduate Medical fournal 1994; 70: 818-20.

42 Murphy DJ, Burrows D, Santilli S, et al. The influence of the probability of survival on patients' preferences regarding cardiopulmonary resuscitation. New England fournal of Medicine 1994; 330: 545-9.

43 Frankl D, Oye RK, Bellamy PE. Attitudes of hospitalised patients toward life support: a survey of 200 inpatients. American fournal of Medicine 1989; 86: 645-8.

44 Wagner A. Cardiopulmonary resuscitation in the aged. A prospective survey. New England fournal of Medicine 1984; 310: 1129-30.

45 Füsgen I, Summa J-D. How much sense is there in an attempt to resuscitate an aged person? Gerontology 1978; 24: 37-45.

46 Starr TJ, Pearlman RA, Uhlmann RF. Quality of life and resuscitation decisions in elderly patients. fournal of General Internal Medicine 1986; 1: 373-9.

47 Jorm AF, Henderson AS, Scott R, Korten AE, Christensen $\mathrm{H}$, Mackinnon AJ. Factors associated with 
the wish to die in elderly people. Age and Ageing 1995; 24: 389-92.

48 Torian LV, Davidson EJ, Fillit HM, Fulop G, Sell LL. Decisions for and against resuscitation in an acute geriatric medicine unit serving the frail elderly. Archives of Internal Medicine 1992; 152: 561-5.

49 Bruce-Jones P, Roberts H, Bowker L, Cooney V. Resuscitating the elderly: what do the patients want? Fournal of Medical Ethics 1996; 22: 154-9.

50 Lo B, McLeod GA, Saika G. Patient attitudes to discussing life-sustaining treatment. Archives of Internal Medicine 1986; 146: 1613-5.

51 Bedell SE, Delbanco TL. Choices about cardiopulmonary resuscitation in the hospital. When do physicians talk with patients? New England fournal of Medicine 1984; 310: 1089-93.

52 Pearlman RA, Uhlmann RF. Quality of life in chronic diseases: perceptions of elderly patients. fournal of Gerontology 1988; 43: M25-M30.

53 Hill ME, MacQuillan G, Forsyth M, Heath DA. Cardiopulmonary resuscitation: who makes the decision? British Medical fournal 1994; 308: 1677.

54 Murphy DJ, Murray AM, Robinson BE, Campion EW. Outcomes of cardiopulmonary resuscitation in the elderly. Annals of Internal Medicine 1989; 111: 199-205.
55 Podrid PJ. Resuscitating the elderly: a blessing or a curse? Annals of Internal Medicine 1989; 111: 193-5.

56 British Medical Association and Royal College of Nursing. Decisions relating to cardiopulmonary resuscitation. Joint statement in association with the resuscitation Council (UK). London, 1993.

57 The Law Commission. Mental incapacity. Law Com No 231. London: HMSO, 1995.

58 Aarons EJ, Beeching NJ. Survey of "do not resuscitate" orders in a district general hospital. British Medical fournal 1991; 303: 1504-6.

59 Kohn M, Menon G. Life prolongation: views of elderly outpatients and health care professionals. Fournal of the American Geriatrics Society 1988; 36: 840-4.

60 Schade SG, Muslin H. Do not resuscitate decisions: discussions with patients. Fournal of Medical Ethics 1989; 15: 186-90.

61 Kellogg FR, Crain M, Corwin J, Brickner PW. Lifesustaining interventions in frail elderly persons. Talking about choices. Archives of Internal Medicine 1992; 152: 2317-20.

62 Jackson DL, Younger S. Patient autonomy and "death with dignity". Some clinical caveats. New England fournal of Medicine 1979; 301: 404-8.

News and notes

\section{UNESCO Asian Bioethics Conference}

A tentative date for the UNESCO Asian Bioethics Conference has been announced. It is proposed to hold the conference from the 29th of October to the 2nd November 1997. The venues are Kobe and Fukui in Japan.

Topics include: The Human Genome Project and applications of the knowledge; Bioethics education and training; International cooperation, and Universal and cross-cultural bioethics.

For further information please contact: Emeritus Professor Norio Fujiki, Secretary General, UNESCO ABC'97, Department of Internal Medicine, Fukui Medical School, Matsuokacho, Fukui 910-11, Japan. Tel: +81-776-61-311, ext 2300; fax: +81-776-61-8110.

\section{News and notes}

\section{Nuffield Council on Bioethics}

Dr Onora O'Neill, CBE, FBA has been appointed Chairman of the Nuffield Council on Bioethics in succession to the Rt Hon Sir Patrick Nairne, GCB, MC.

Dr O'Neill has been Principal of Newnham since 1992 and a member of the Nuffield Council on Bioethics since its establishment in 1991. She has written widely on ethics and political philosophy. Her two most recent books are Faces of Hunger: An Essay on Poverty, Development and fustice (1986) and Constructions of Reason: Exploration of Kant's Practical Philosophy (1989); Towards fustice and Virtue will appear in 1996. She is a past-President of the Aristotelian Society and a past member of the Home Office's Animal Procedures Committee.

The following new members have joined the Nuffield Council on Bioethics: the Revd Professor Duncan Forrester, Principal of New College, University of Edinburgh; Professor Brian Heap, CBE, FRS, lately Director of Research, the Brabaham Institute; Lady Hornby, Chairman, Gloucestershire Royal NHS Trust and $\mathrm{Mr}$ Derek Osborn, CB, Chairman of the European Environment Agency. 